\title{
Facile Synthesis of $\mathrm{Zn}_{x} \mathrm{Cd}_{1-x} \mathrm{~S}$ Solid Solution Microspheres through Ultrasonic Spray Pyrolysis for Improved Photocatalytic Activity
}

\author{
Jianhui Huang, ${ }^{1,2}$ Wenting Lin, ${ }^{1}$ Liyan Xie, ${ }^{1,2}$ and Wingkei $\mathrm{Ho}^{3}$ \\ ${ }^{1}$ College of Environmental and Biological Engineering, Putian University, Putian 351100, China \\ ${ }^{2}$ Fujian Provincial Key Laboratory of Ecology-Toxicological Effects and Control for Emerging Contaminants, College of Environmental \\ and Biological Engineering, Putian University, Putian 351100, China \\ ${ }^{3}$ Department of Science and Environmental Studies, The Education University of Hong Kong, Tai Po, New Territories, Hong Kong
}

Correspondence should be addressed to Jianhui Huang; owenhuang95@163.com and Wingkei Ho; keithho@eduhk.hk

Received 11 January 2017; Revised 27 March 2017; Accepted 11 April 2017; Published 14 May 2017

Academic Editor: K. K. R. Datta

Copyright (C) 2017 Jianhui Huang et al. This is an open access article distributed under the Creative Commons Attribution License, which permits unrestricted use, distribution, and reproduction in any medium, provided the original work is properly cited.

\begin{abstract}
Nanocrystal $\mathrm{Zn}_{x} \mathrm{Cd}_{1-x} \mathrm{~S}$ solid solutions were successfully prepared using a facile and reproducible method of ultrasonic spray pyrolysis with $\mathrm{Cd}(\mathrm{Ac})_{2} \cdot 2 \mathrm{H}_{2} \mathrm{O}, \mathrm{ZnCl}_{2}$, and thiourea as precursors. Scanning electron microscopy and transmission electron microscopy images show that the prepared particles possess microspherical morphology. The band gaps of the solid solutions can be tuned by changing the constituent stoichiometries of $\mathrm{Cd}$ and $\mathrm{Zn}$. The X-ray diffraction peaks gradually shift to small angle, and the absorption edge shifts to long wavelength with increasing Cd molar fraction in the solid solution. The sample prepared at the $\mathrm{Cd} / \mathrm{Zn}$ ratio of $1: 1$ displays the optimal activity by using the photocatalytic degradation of methyl orange in the aqueous solution as model reactions under visible light irradiation. This study provides an effective route to prepare spherical ternary photocatalysts with mesoporous structure for further investigations and practical applications.
\end{abstract}

\section{Introduction}

The controlled fabrication, characterization, and application of semiconductor nanomaterials with functional properties have attracted significant interest owning to their novel properties and promising applications in electrical, optoelectronic, and photochemical fields. The band gap energy of a semiconductor nanostructure is an important parameter for their applications. Band gap tuning has attracted considerable attention particularly in the region of photocatalysis, which requires suitable band gap and band position. Changing the size of nanostructured semiconductors is a common method used to tune their band gap due to the quantum confinement effect [1-3]. However, the physical and chemical properties of semiconductors are significantly influenced by their sizes; hence, changing the sizes of single-component semiconductor nanostructures has limited applications because of the possible alterations in the properties of the material. Doping with guest elements is another commonly utilized method, but both dopant type and concentration are difficult to control $[4,5]$. Upon this, ternary semiconductor materials have gained considerable attention as their properties could be controlled by their morphology, particle size, and constituent stoichiometries. For example, $\mathrm{Zn}_{x} \mathrm{Cd}_{1-x} \mathrm{~S}[6,7]$, a ternary II-VI semiconductor material, is formed using the solid solution of CdS with a narrow band gap of $2.4 \mathrm{eV}[8,9]$ and $\mathrm{ZnS}$ with a wide band gap of $3.7 \mathrm{eV}$ [10]. Consequently, $\mathrm{Zn}_{x} \mathrm{Cd}_{1-x} \mathrm{~S}$ nanocrystals can form a series of semiconductors, whose band gap can be continuously tunable and cover the absorption light range from visible to ultraviolet [11, 12]. Up to now, the $\mathrm{Zn}_{x} \mathrm{Cd}_{1-x} \mathrm{~S}$ have been extensively researched in the organic pollutant degradation as efficient photocatalyst.

Currently, various strategies are employed in the synthesis of $\mathrm{Zn}_{x} \mathrm{Cd}_{1-x} \mathrm{~S}$ nanostructures including chemical precipitation methods [13-15], hydrothermal or solvothermal reactions [10, 16-19], and chemical reduction processes [20]. In many cases, the synthesized $\mathrm{Zn}_{x} \mathrm{Cd}_{1-x} \mathrm{~S}$ were applied to the degradation of organic dyes [10,15-17] such as methyl 
TABLE 1: Composition ( $\mathrm{Zn} / \mathrm{Cd}$ molar ratio) of the reactant solutions and the resulting $\mathrm{Zn}_{x} \mathrm{Cd}_{1-x} \mathrm{~S}$ microspheres.

\begin{tabular}{|c|c|c|c|c|c|}
\hline Samples & $\mathrm{ZnS}$ & $\mathrm{Zn}_{0.75} \mathrm{Cd}_{0.25} \mathrm{~S}$ & $\mathrm{Zn}_{0.50} \mathrm{Cd}_{0.50} \mathrm{~S}$ & $\mathrm{Zn}_{0.25} \mathrm{Cd}_{0.75} \mathrm{~S}$ & $\mathrm{CdS}$ \\
\hline Molar ration of $\mathrm{Zn} / \mathrm{Cd}$ in precursor & $1: 0$ & $3: 1$ & $1: 1$ & $1: 3$ & $0: 1$ \\
\hline$x$ of $\mathrm{Zn}_{x} \mathrm{Cd}_{1-x} \mathrm{~S}$ in product ${ }^{\mathrm{a}}$ & - & 0.73 & 0.47 & 0.24 & 0.01 \\
\hline Abortion edge (nm) & 335 & 390 & 454 & 484 & 525 \\
\hline Band gap $(\mathrm{eV})$ & 3.7 & 3.2 & 2.7 & 2.6 & 2.4 \\
\hline
\end{tabular}

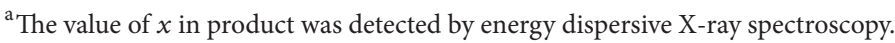

orange (MO), which is genotoxic [21] and carcinogenic [22] and difficult to degrade using conventional treatment processes. However, these traditional synthesis methods usually require severe conditions, such as high temperature, high pressure, toxic agent, or complicated equipment. In addition, most of them cannot be used for continuous fabrication, thereby limiting their application for mass production. Thus, a continuous method for synthesis of $\mathrm{Zn}_{x} \mathrm{Cd}_{1-x} \mathrm{~S}$ with special nanostructures and high yield must be developed to improve the design of high-performance materials for various applications.

In this paper, we report a convenient, new method for continuous synthesis of $\mathrm{Zn}_{x} \mathrm{Cd}_{1-x} \mathrm{~S}$ microspheres through ultrasonic spray pyrolysis. The synthesized $\mathrm{Zn}_{x} \mathrm{Cd}_{1-x} \mathrm{~S}$ microspheres exhibit composition-dependent band gap energies and light absorption properties. The synthesized $\mathrm{Zn}_{x} \mathrm{Cd}_{1-x} \mathrm{~S}$ could be used to efficiently degrade organic pollutants in water.

\section{Experimental Section}

2.1. Catalyst Preparation. For synthesis of $\mathrm{Zn}_{x} \mathrm{Cd}_{1-x} \mathrm{~S}(0<$ $x<1), 4 x \mathrm{mmol} \mathrm{ZnCl}_{2}, 4(1-x) \mathrm{mmol}$ cadmium acetate $\left[\mathrm{Cd}\left(\mathrm{CH}_{3} \mathrm{COO}\right)_{2} \cdot 2 \mathrm{H}_{2} \mathrm{O}\right]$, and $20 \mathrm{mmol}$ thiourea $\left[\mathrm{CS}\left(\mathrm{NH}_{2}\right)_{2}\right]$ were added to $200 \mathrm{~mL}$ of deionized water under magnetic stirring to form a transparent colorless solution. The solution was nebulized by an ultrasonic atomizer (YUYUE402AI, Shanghai) at $1.7 \mathrm{MHz} \pm 10 \%$ and carried by air through a quartz tube with a flow rate of $10 \mathrm{~L} / \mathrm{min}$ in a furnace thermostated at $500^{\circ} \mathrm{C}$. The quartz reaction tube is $1 \mathrm{~m}$ in length with a diameter of $3.5 \mathrm{~cm}$. The products were collected in a percolator with distilled water, separated by centrifugation, and washed thoroughly with distilled water and ethanol. The product was vacuum dried at $80^{\circ} \mathrm{C}$ for $2 \mathrm{~h}$. A series of $\mathrm{Zn}_{x} \mathrm{Cd}_{1-x} \mathrm{~S}$ microspheres were synthesized by adjusting the ratio of the reactants, namely, $\mathrm{ZnCl}_{2}$ and $\mathrm{Cd}\left(\mathrm{CH}_{3} \mathrm{COO}\right)_{2} \cdot 2 \mathrm{H}_{2} \mathrm{O}$ (Table 1$)$. The $\mathrm{Zn}_{x} \mathrm{Cd}_{1-x} \mathrm{~S}$ powder was obtained with a yield of 50 90\% which depended on the constituent stoichiometries of $\mathrm{Zn}_{x} \mathrm{Cd}_{1-x} \mathrm{~S}$.

2.2. Characterization. The crystal structures and phase states of the synthesized materials were determined by X-ray diffractometry (XRD) on a Bruker D8 Advance X-ray diffractometer with $\mathrm{Cu} \mathrm{Ka}$ radiation $(\lambda=1.54178 \AA)$ at a scanning rate of $0.05^{\circ} 2 \theta / \mathrm{s}$ and the scanning range was $10-80^{\circ}$. The morphologies of samples were observed with a scanning electron microscopy (JEOL JSM-6300F) operated at an accelerating voltage of $25 \mathrm{kV}$. Transmission electron microscopy
(TEM) images were measured by using a Philips CM-120 electron microscopy instrument. UV-vis diffuse reflection spectroscopy (DRS) was performed on a Varian Cary 100 Scan UV-visible system equipped with Labsphere diffuse reflectance accessory using $\mathrm{BaSO}_{4}$ as the reference material. The reflection spectra were converted to absorbance spectra by Kubelka-Munk method. Brunauer-Emmett-Teller (BET) surface areas and pore volume were determined by $\mathrm{N}_{2}$ adsorption/desorption isotherms measurements at $77 \mathrm{~K}$ by using an automated nitrogen adsorption analyzer (ASAP 2020, Micromeritics, America). The samples were degassed under vacuum at $120^{\circ} \mathrm{C}$ and kept for $5 \mathrm{~h}$ before data acquisition.

2.3. Evaluation of Photocatalytic Activity. The photocatalytic activities of the $\mathrm{Zn}_{x} \mathrm{Cd}_{1-x} \mathrm{~S}$ were evaluated by degrading of methyl orange (MO) in aqueous solution under visible light irradiation. In the typical photocatalytic degradation experiment process, the tested catalyst $(40 \mathrm{mg}$ ) was suspended in a $100 \mathrm{~mL}$ Pyrex glass vessel containing MO aqueous solution $(80 \mathrm{~mL}, 10 \mathrm{ppm})$ to produce a suspension at room temperature with the magnetic stirring. The suspension was stirred in darkness for $2 \mathrm{~h}$ to achieve the adsorption equilibrium. The $300 \mathrm{~W}$ halogen lamp (Philips Electronics) with a $420 \mathrm{~nm}$ cutoff filter was used as visible light source which was positioned beside a cylindrical reaction vessel with a flat side. The system was water cooled to maintain the temperature. In a certain time, $3 \mathrm{~mL}$ of the reaction suspension was collected and centrifuged at $6000 \mathrm{rpm}$ for $3 \mathrm{~min}$ to remove the catalyst. The residual pollution concentration was collected and analyzed using a Varian Cary 50 Scan UV/vis spectrophotometer.

\section{Results and Discussion}

3.1. Structure. Figure 1 shows the XRD patterns of the asprepared $\mathrm{ZnS}, \mathrm{Zn}_{x} \mathrm{Cd}_{1-x} \mathrm{~S}$, and $\mathrm{CdS}$ samples. The sizebroadening effects can be found in all of the XRD patterns, indicating the finite size of the samples. For CdS and $\mathrm{Zn}_{x} \mathrm{Cd}_{1-x} \mathrm{~S}$ samples, the XRD patterns show strong characteristic peaks of (100), (002), (101), (102), (110), (103), and (112), which can be indexed as wurtzite-phase structure. For $\mathrm{ZnS}$ sample, the XRD pattern mainly reflects three strong peaks of (111), (220), and (311), which can be indexed as a zincblende structure with weak wurtzite. The diffraction peaks of $\mathrm{CdS}$ and $\mathrm{Zn}_{x} \mathrm{Cd}_{1-x} \mathrm{~S}$ gradually shift to larger angles with increasing $\mathrm{Zn}$ content. This finding also indicates that no phase separation occurs during nucleation of $\mathrm{ZnS}$ or $\mathrm{CdS}$ in the $\mathrm{Zn}_{x} \mathrm{Cd}_{1-x} \mathrm{~S}$ samples [23]. 


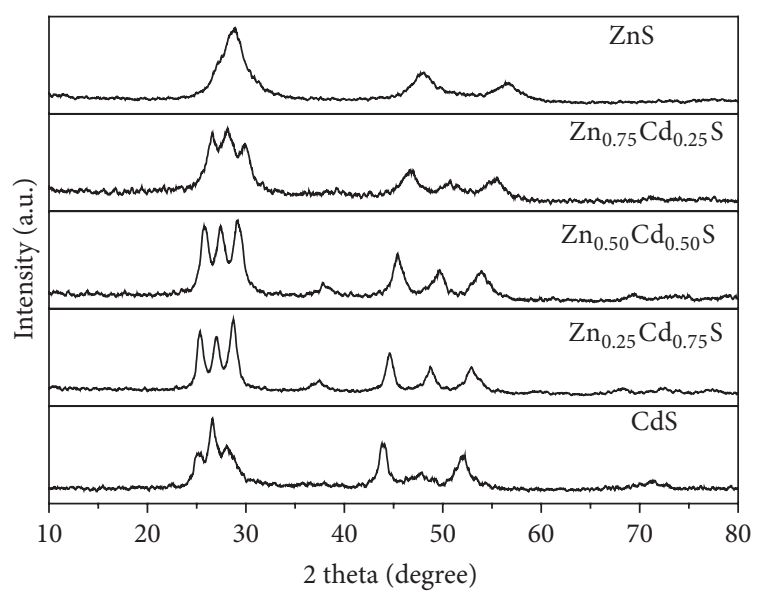

FIGURE 1: X-ray diffraction patterns of CdS, $\mathrm{Zn}_{x} \mathrm{Cd}_{1-x} \mathrm{~S}$, and $\mathrm{ZnS}$ samples.

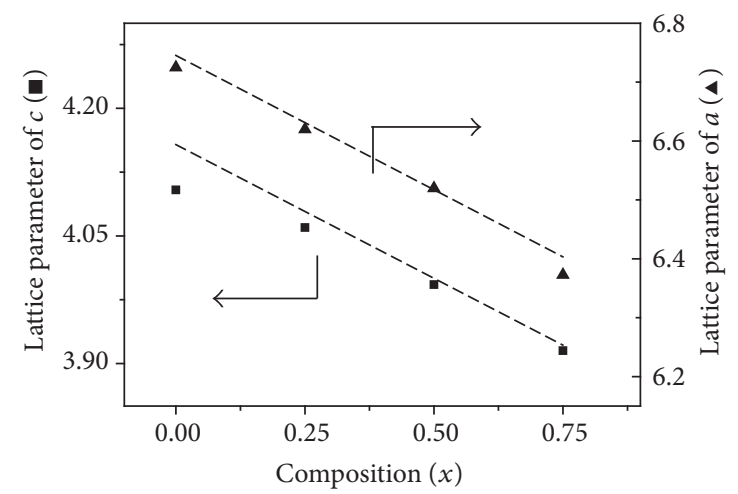

FIgURE 2: Composition dependence of the cell constants $a(\mathbf{\Delta})$ and $c(\boldsymbol{\square})$ axis values of $\mathrm{Zn}_{x} \mathrm{Cd}_{1-x} \mathrm{~S}$ spheres as a function of $\mathrm{Zn}$ content $(x)$. The solid line was calculated using Vegard's law.

The lattice constants $a$ and $c$ for the hexagonal phase of $\mathrm{Zn}_{x} \mathrm{Cd}_{1-x} \mathrm{~S}$ are calculated using the following equation[24]:

$$
\frac{1}{d}=\sqrt{\frac{4}{3}\left(\frac{h^{2}+h k+k^{2}}{a^{2}}\right)+\frac{l^{2}}{c^{2}}}
$$

As shown in Figure 2, the value of lattice constants " $a$ " and " $c$ " exhibits nearly linear relationship to $\mathrm{Zn}$ composition in the region of $0-0.75$. The linear relationship almost obeys the empirical formulations of Vegard's law [25-27], which suggests that the $\mathrm{Zn} / \mathrm{Cd}$ ratio in the produced $\mathrm{Zn}_{x} \mathrm{Cd}_{1-x} \mathrm{~S}$ is almost the same as the ratio of the reactants. This trend also confirms that the as-prepared samples underwent homology formation without separating $\mathrm{ZnS}$ and $\mathrm{CdS}$ phases.

3.2. Morphology. Figures 3(a), 3(b), and 3(c) depict the SEM images of the as-prepared $\mathrm{ZnS}$, CdS, and $\mathrm{Zn}_{0.50} \mathrm{Cd}_{0.50} \mathrm{~S}$, respectively. All samples prepared with ultrasonic spray pyrolysis consist entirely of spheres, with size ranging from $100 \mathrm{~nm}$ to $1.0 \mu \mathrm{m}$. During preparation, the use of ultrasonic nebulizer endows the samples with a spherical morphology, which could generate aerosol containing $\mathrm{Zn}$ and $\mathrm{Cd}$ ions as well as thiourea. These aerosols would serve as microreactors when carried into a tubular reactor with constant air flow rate under pyrolysis conditions. At high temperatures, water in aerosols evaporates quickly. Thiourea in the droplet decomposes and releases $\mathrm{H}_{2} \mathrm{~S}$, which would quickly react with $\mathrm{Zn}$ and $\mathrm{Cd}$ ions in the aerosols to generate spherical products. The product dimension is determined by the size of droplets in the aerosol, which could be adjusted by controlling the nebulizing condition.

The typical high-magnified TEM image of the $\mathrm{Zn}_{0.50} \mathrm{Cd}_{0.50} \mathrm{~S}$ sphere shows that the prepared spheres are composed of small nanoparticles and exhibit porous structure (Figure 3(d)). The porous surface with nanosized crystal structure improves adsorptivity, which is vital for catalytic applications. The composition of the $\mathrm{Zn}_{0.50} \mathrm{Cd}_{0.50} \mathrm{~S}$ sphere was determined by energy dispersive $\mathrm{X}$-ray spectroscopy (EDX). The results indicate that the asprepared samples contain $\mathrm{Zn}, \mathrm{Cd}$, and $\mathrm{S}$, and some of the $\mathrm{Cu}$ signal originates from the substrate (Figure 3(e)). Moreover, the $\mathrm{Zn} / \mathrm{Cd}$ ratio in the produced $\mathrm{Zn}_{x} \mathrm{Cd}_{1-x} \mathrm{~S}$ microspheres is almost identical to that in the precursor solution (Table 1). This finding suggests that $\mathrm{Zn}$ and $\mathrm{Cd}$ in the precursor have reacted completely. These results are consistent with the result deduced with Vegard's law. Excess thiourea in the precursor supplies sufficient sulfides to ensure that $\mathrm{Zn}^{2+}$ and $\mathrm{Cd}^{2+}$ react completely. Hence, the composition of $\mathrm{Zn}_{x} \mathrm{Cd}_{1-x} \mathrm{~S}$ can be easily and accurately adjusted using the proposed synthesis method.

\subsection{UV-Vis Diffuse Reflectance Spectroscopy and Band Struc-} ture. An optimal photocatalytic material exhibits appropriate band position and band gap that absorbs light in the visible range. Figure 4(a) shows the UV-visible absorption spectra of samples prepared with different ratios of $\mathrm{Zn} / \mathrm{Cd}$. The spectra indicate a typical semiconductor absorption behavior. The absorption edges of the samples gradually red shift from $335 \mathrm{~nm}$ to $525 \mathrm{~nm}$ with increasing Cd content, indicating the narrowing of the band gaps. The inset in Figure 4 represents the suspension of the samples whose color changes from white to orange. Hence, the range of light absorption can be adjusted from ultraviolet to blue-green light. The band gaps calculated from the onset of the absorbance edge spectra for each catalyst are presented in Table 1 . All the samples of $\mathrm{Zn}_{x} \mathrm{Cd}_{1-x} \mathrm{~S}$ show band gaps between $\mathrm{CdS}(2.4 \mathrm{eV})$ and $\mathrm{ZnS}(3.7 \mathrm{eV})$. This large shift in the absorbance edge should be attributed to the changes in the composition rather than the quantum size effects. The compositional variation of $\mathrm{Zn}_{x} \mathrm{Cd}_{1-x} \mathrm{~S}$ solid solutions affects their band gap, because the replacement of $\mathrm{Cd}$ cations by $\mathrm{Zn}$ in the crystal lattice modifies the position of the conduction band through hybridization of the Cd 5s5p level with the negative $\mathrm{Zn} 4 \mathrm{~s} 4 \mathrm{p}$ level $[28,29]$.

Figure $4(\mathrm{~b})$ shows the estimated $E_{\mathrm{CB}}$ and $E_{\mathrm{VB}}$ edge potentials of $\mathrm{Zn}_{x} \mathrm{Cd}_{1-x} \mathrm{~S}$ microspheres calculated using (2) and (3), respectively [30,31]:

$$
\begin{aligned}
& E_{\mathrm{CB}}=\left(X_{\mathrm{Cd}}^{1-x} X_{\mathrm{Zn}}^{x} X_{\mathrm{S}}^{1}\right)^{1 / 2}-\frac{1}{2} E_{g}+E_{0}, \\
& E_{\mathrm{VB}}=E_{\mathrm{CB}}+E_{g},
\end{aligned}
$$




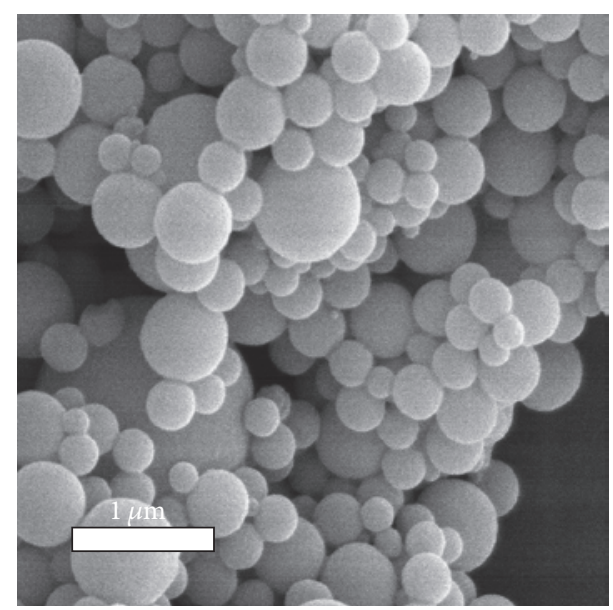

(a)

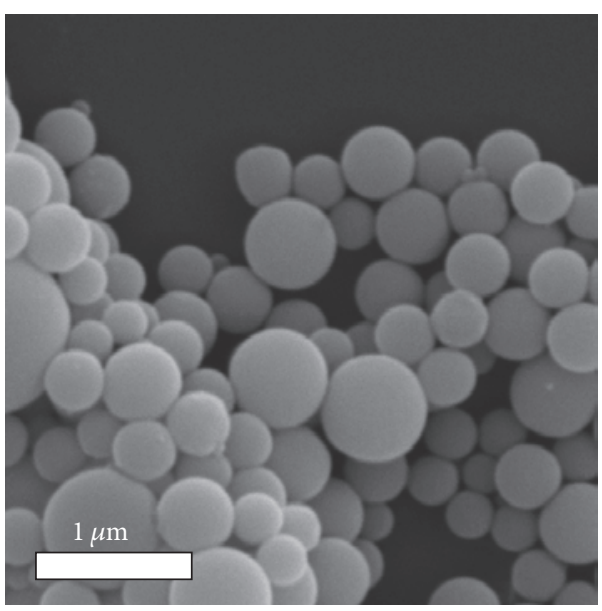

(c)

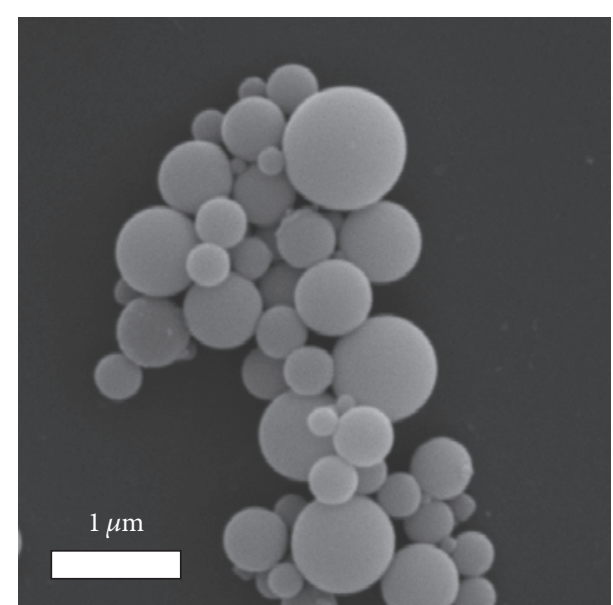

(b)

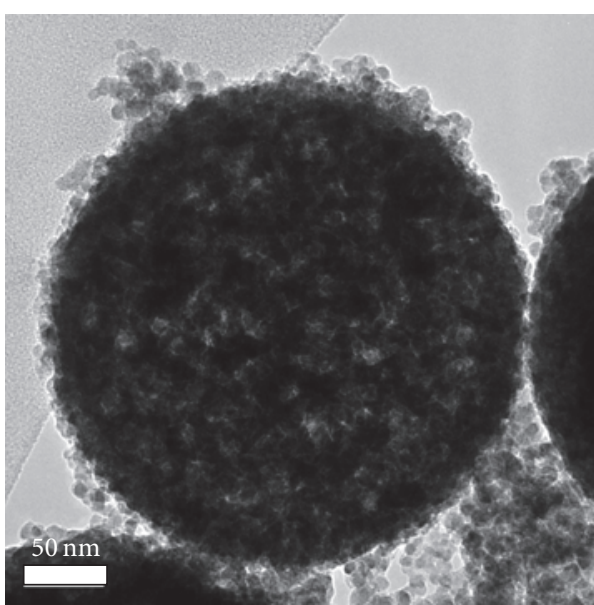

(d)

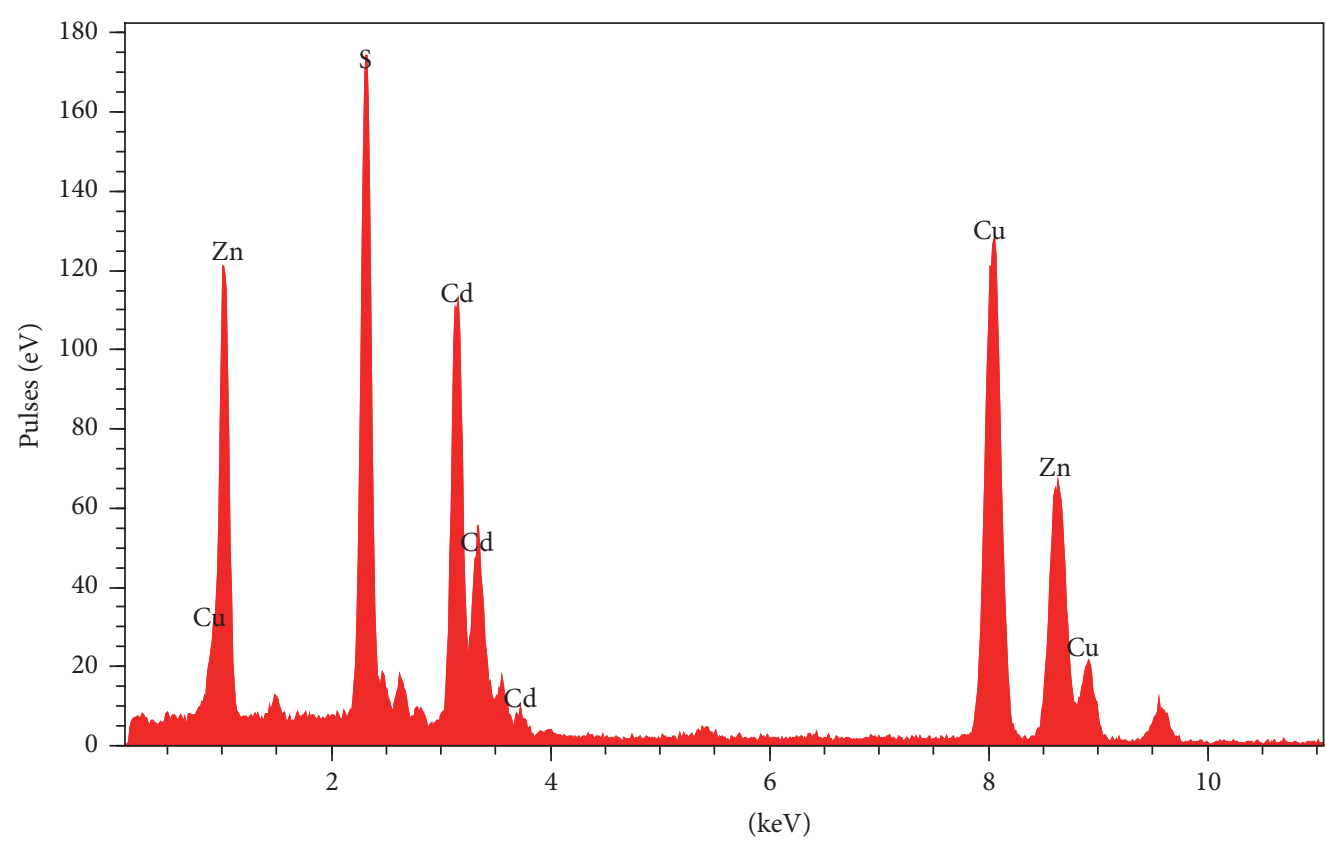

(e)

FIGURE 3: Scanning electron microscopy (SEM) and transmission electron microscopy (TEM) images of the prepared samples: (a) SEM of CdS, (b) SEM of ZnS, (c) SEM of $Z_{0.50} \mathrm{Cd}_{0.50} \mathrm{~S}$, (d) TEM of $\mathrm{Zn}_{0.50} \mathrm{Cd}_{0.50} \mathrm{~S}$, and (e) energy dispersive X-ray analysis spectra of $\mathrm{Zn}_{0.50} \mathrm{Cd}{ }_{0.50} \mathrm{~S}$. 


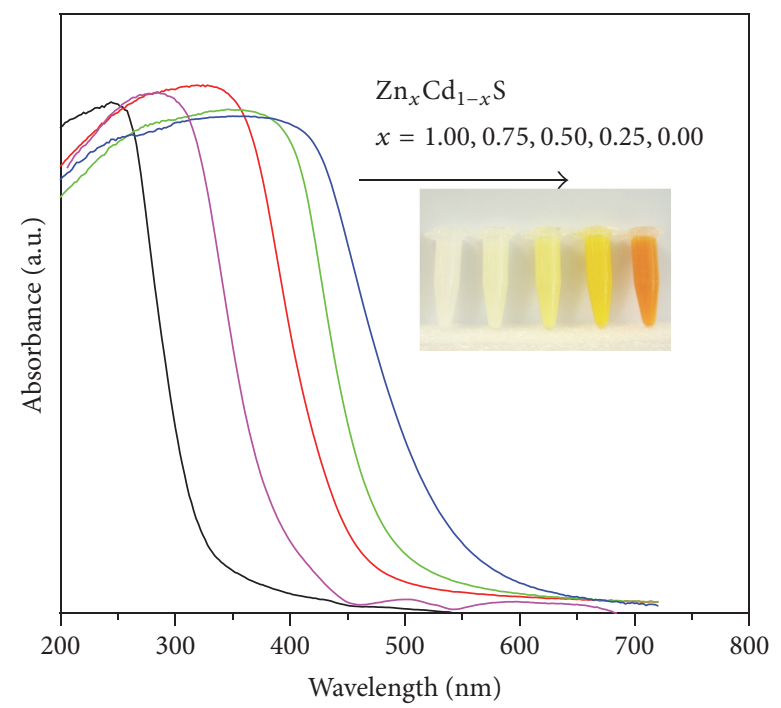

(a)

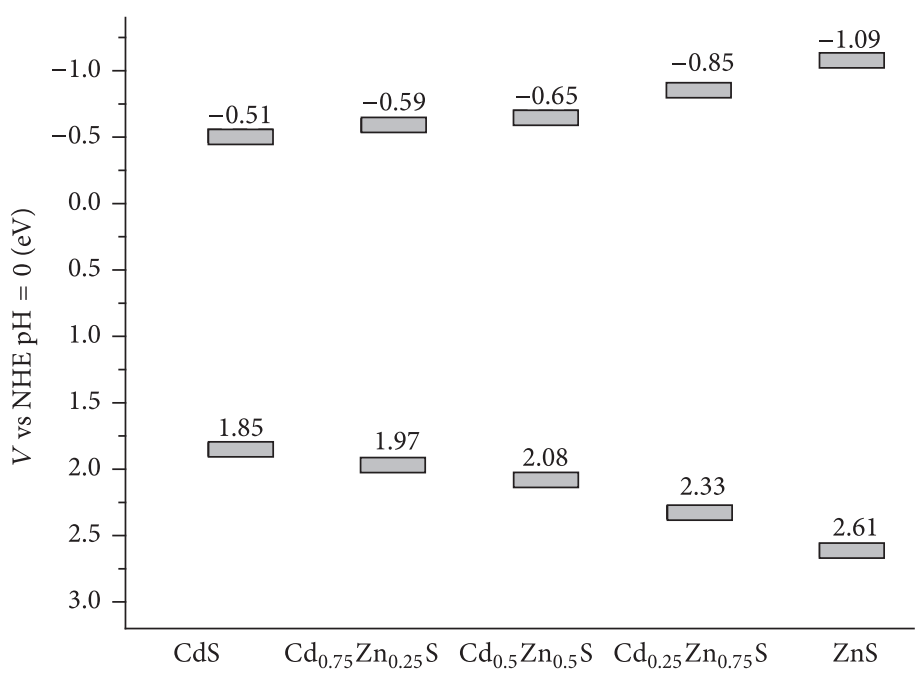

(b)

FIGURE 4: (a) Diffuse reflectance UV-vis spectra and the aqueous solution image (inset) of CdS, $\mathrm{Zn}_{x} \mathrm{Cd}_{1-x} \mathrm{~S}$, and ZnS samples. (b) Conduction and valence band edge potentials of $\mathrm{Zn}_{x} \mathrm{Cd}_{1-x} \mathrm{~S}$ obtained by theoretical calculation.

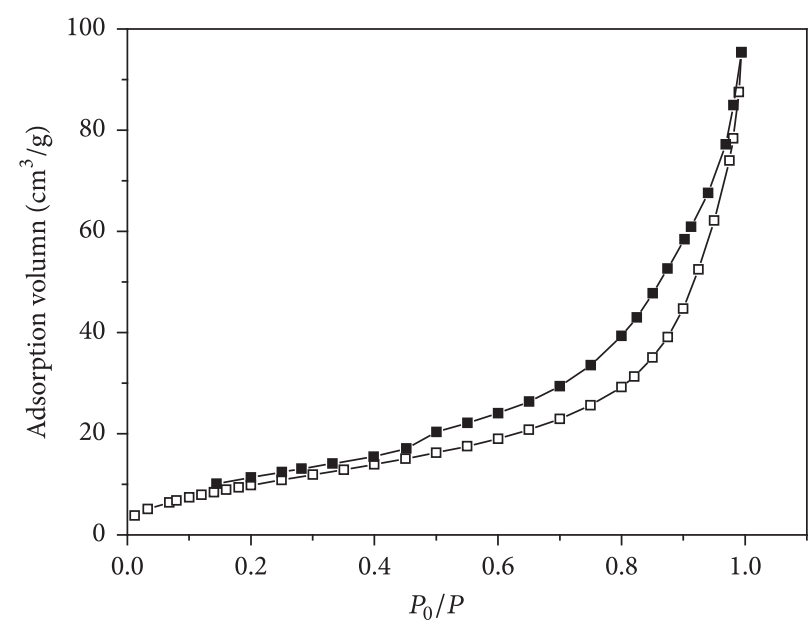

(a)

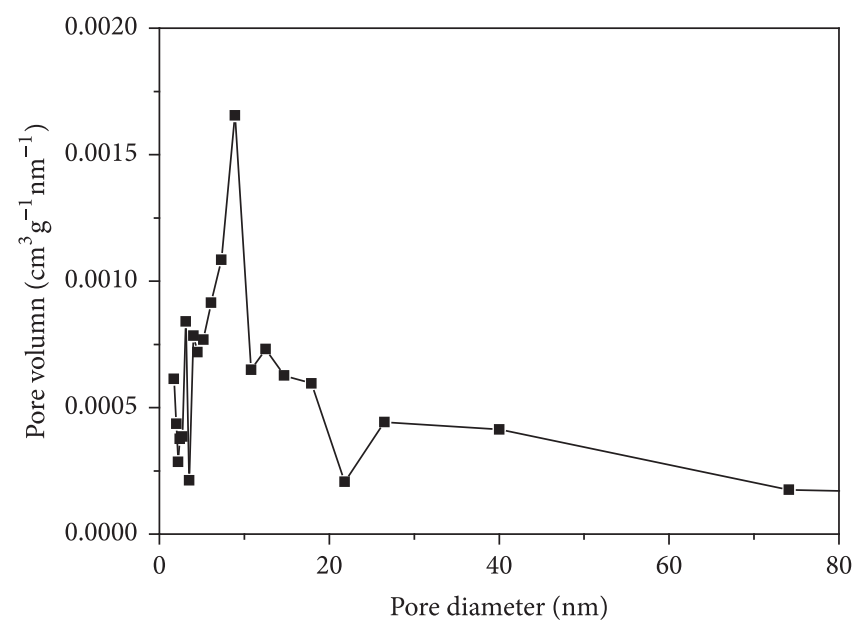

(b)

FIGURE 5: $\mathrm{N}_{2}$ physisorption results at $77 \mathrm{~K}$ of $\mathrm{Zn}_{0.50} \mathrm{Cd}_{0.50} \mathrm{~S}$. (a) Adsorption-desorption isotherms (open and filled symbols correspond to the adsorption and desorption branches, resp.). (b) Pore size distributions derived from the desorption branches using the Barrett-Joyner-Halenda method.

where $X_{\mathrm{Cd}}, X_{\mathrm{Zn}}$, and $X_{\mathrm{S}}$ are $4.3,4.45$, and $6.22 \mathrm{eV}$, respectively, which correspond to the absolute electronegativities of the constituent atoms, namely, $\mathrm{Cd}, \mathrm{Zn}$, and $\mathrm{S}$, respectively. $E_{\mathrm{CB}}$ and $E_{\mathrm{VB}}$ are the conduction band minimum and valence band maximum of $\mathrm{Zn}_{x} \mathrm{Cd}_{1-x}$ S, respectively. $E_{g}$ is the bandgap energy of $\mathrm{Zn}_{x} \mathrm{Cd}_{1-x} \mathrm{~S}$ which was determined by UV-vis diffuse reflectance spectra (DRS), and $E_{0}=$ $-4.5 \mathrm{eV}_{\text {VAS }}$ at $\mathrm{pH}=0$ [30]. The results indicate that the band position can be tuned by changing the constituent stoichiometries of $\mathrm{Zn}_{x} \mathrm{Cd}_{1-x} \mathrm{~S}$. Taking $\mathrm{Cd}_{0.50} \mathrm{Zn}_{0.50} \mathrm{~S}$ microspheres, for example, the $E_{\mathrm{CB}}(-0.65 \mathrm{eV})$ and $E_{\mathrm{VB}}$ edge levels $(-0.65 \mathrm{eV})$ are more negative and positive than those of CdS. Hence, $\mathrm{Cd}_{0.50} \mathrm{Zn}_{0.50} \mathrm{~S}$ can be excited by visible light, and its photogenerated charge carriers possess stronger redox ability than that of CdS. Therefore, $\mathrm{Cd}_{0.50} \mathrm{Zn}_{0.50} \mathrm{~S}$ may have promising photocatalytic performance for highly efficient organic pollutant degradation.

3.4. BET Surface Areas. Figure 5 shows the nitrogen adsorption-desorption isotherms and Barrett-Joyner-Halenda (BJH) pore size distribution plots of $\mathrm{Cd}_{0.50} \mathrm{Zn}_{0.50} \mathrm{~S}$. Nitrogen adsorption measurements demonstrate that the prepared $\mathrm{Zn}_{0.50} \mathrm{Cd}_{0.50} \mathrm{~S}$ exhibits type IV isotherm behavior, which is representative of mesoporous solids. The specific surface of $\mathrm{Zn}_{0.50} \mathrm{Cd}_{0.50} \mathrm{~S}$ calculated by multipoint BET method is $51 \mathrm{~m}^{2} / \mathrm{g}$. The $\mathrm{BJH}$ pore size analysis (utilizing the isotherm 


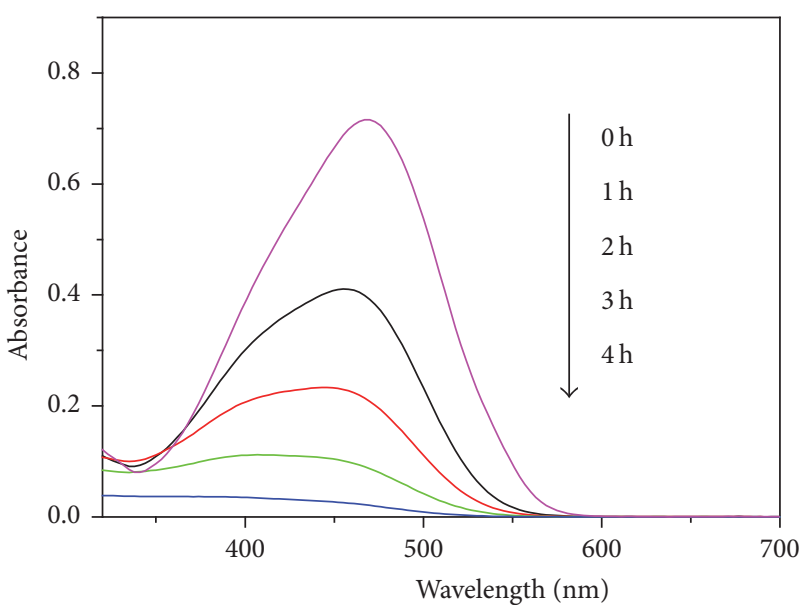

(a)

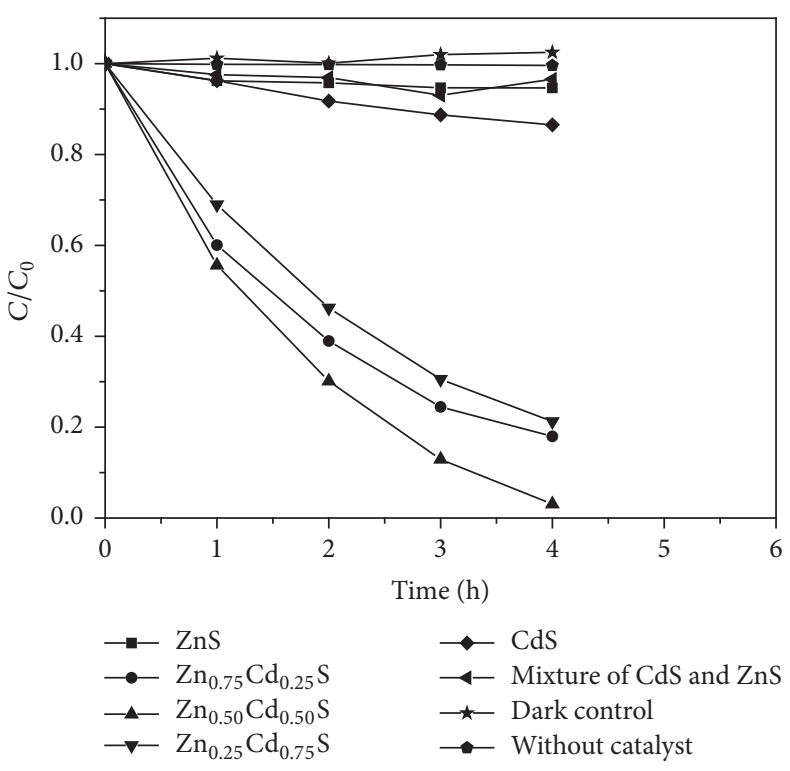

(b)

FIGURE 6: The concentration changes of methyl orange under different conditions.

desorption branch) shows that the sphere has a wide pore size distribution, ranging from $0 \mathrm{~nm}$ to $80 \mathrm{~nm}$ and peaking at $10 \mathrm{~nm}$ with a pore volume of $0.13 / \mathrm{g}$ (Figure $5(\mathrm{~b})$ ).

3.5. Photocatalytic Performance. The photocatalytic activity of $\mathrm{Zn}_{x} \mathrm{Cd}_{1-x} \mathrm{~S}$ nanoparticles was evaluated by degradation of $\mathrm{MO}$ molecules in water. The control experiment was performed before the test without using any photocatalyst. Figure 6 shows the changes in the concentration of MO in the presence of photocatalysts and under irradiation of visible light $(\lambda>420 \mathrm{~nm})$. Figure 6(a) shows that the main absorption peak of $\mathrm{MO}(\lambda=464 \mathrm{~nm})$ nearly disappears after $4 \mathrm{~h}$ of irradiation in the presence of $\mathrm{Zn}_{0.50} \mathrm{Cd}_{0.50} \mathrm{~S}$, which indicates that $\mathrm{MO}$ in water is almost completely degraded. The control experiment indicates that MO is stable under the testing conditions without photocatalyst. The concentration of MO is almost invariable in the dark situation indicating that the adsorption equilibrium had been achieved after being stirred in darkness for $2 \mathrm{~h}$. Some comparative experiments were conducted to investigate the liquid-phase photocatalytic activity under different conditions (Figure 6(b)). The $y$-axis of degradation is $C_{t} / C_{0}$. $C_{t}$ is the absorption of $\mathrm{MO}$ at each irradiated time interval at a wavelength of $464 \mathrm{~nm} . C_{0}$ is the absorption of the starting concentration upon reaching the adsorption-desorption equilibrium. Under identical conditions, $\mathrm{Zn}_{x} \mathrm{Cd}_{1-x} \mathrm{~S}$ shows considerably higher activity than that of CdS, ZnS, and mechanically mixed CdS and ZnS. Thus, the visible photocatalytic activity of $\mathrm{Zn}_{x} \mathrm{Cd}_{1-x} \mathrm{~S}$ could be ascribed to the solid solution formation between $\mathrm{CdS}$ and ZnS. In addition, the test shows that the activities of the samples are influenced by their compositions. The photocatalytic conversion of degraded $\mathrm{MO}$ over $\mathrm{Zn}_{0.50} \mathrm{Cd}_{0.50} \mathrm{~S}$ after $4 \mathrm{~h}$ is about $96 \%$, which is higher than that of $\mathrm{Zn}_{0.25} \mathrm{Cd}_{0.75} \mathrm{~S}$ and $\mathrm{Zn}_{0.75} \mathrm{Cd}_{0.25} \mathrm{~S}$; this difference may be ascribed to the

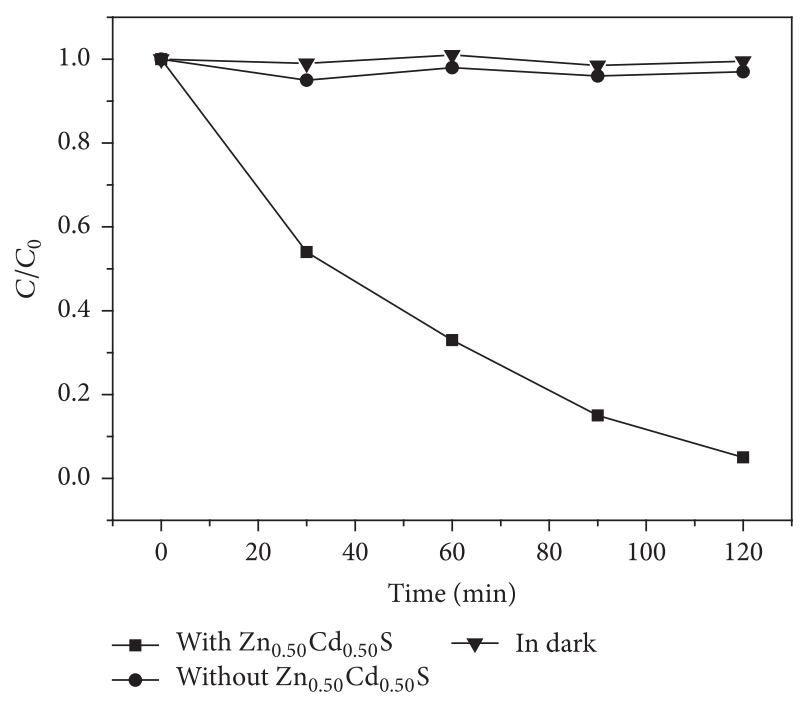

FIGURE 7: The concentration changes of congo red under different conditions.

appropriate band gap and band position of $\mathrm{Zn}_{0.50} \mathrm{Cd}_{0.50} \mathrm{~S}$. The prepared $\mathrm{Zn}_{0.50} \mathrm{Cd}_{0.50} \mathrm{~S}$ was also applied to the degradation of other dyes such as congo red $(10 \mathrm{ppm}, 80 \mathrm{~mL})$. The peak at wavelength of $488 \mathrm{~nm}$ is used to evaluate the degradation of congo red. The result is shown in Figure 7 which indicates that the photocatalytic conversion ratio of congo red was up to $97 \%$ in $120 \mathrm{~min}$ in the presence of $\mathrm{Zn}_{0.50} \mathrm{Cd}_{0.50} \mathrm{~S}$. The control experiment indicates that the congo red is stable without $\mathrm{Zn}_{0.50} \mathrm{Cd}_{0.50} \mathrm{~S}$ under irradiation or with $\mathrm{Zn}_{0.50} \mathrm{Cd}_{0.50} \mathrm{~S}$ in the dark. The result also proved that the prepared $\mathrm{Zn}_{0.50} \mathrm{Cd}_{0.50} \mathrm{~S}$ is effective in degrading organic dye in water.

Figure 8 shows the durability of $\mathrm{Zn}_{0.50} \mathrm{Cd}_{0.50} \mathrm{~S}$ microspheres for the degradation of MO under the same reaction 


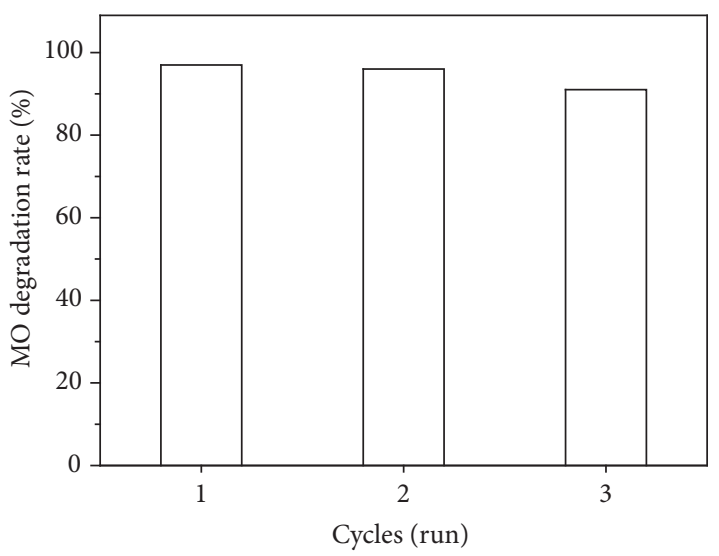

FIGURE 8: Catalyst cycling in the photocatalytic degradation of methyl orange in the presence of $\mathrm{Zn}_{0.50} \mathrm{Cd}_{0.50} \mathrm{~S}$.

conditions. $\mathrm{Zn}_{0.50} \mathrm{Cd}_{0.50} \mathrm{~S}$ microspheres were recovered by being centrifuged without any treatment. The results indicate that the photocatalytic activity of $\mathrm{Zn}_{0.50} \mathrm{Cd}_{0.50} \mathrm{~S}$ did not decrease significantly after three successive cycles. The activity of the photocatalyst was maintained effectively. The slight decrease of $\mathrm{MO}$ degradation rate can be attributed to the reduction of photocatalyst in each sample collection. These results demonstrate that the $\mathrm{Zn}_{0.50} \mathrm{Cd}_{0.50} \mathrm{~S}$ microspheres prepared by ultrasonic spray pyrolysis are stable. In the further study, we also prepared $\mathrm{Zn}_{x} \mathrm{Cd}_{1-x} \mathrm{~S}$ by hydrothermal processes under optimal conditions according to the literature [10] and tested its photocatalytic activity in our conditions. The $\mathrm{Zn}_{0.50} \mathrm{Cd}_{0.50} \mathrm{~S}$ prepared by ultrasonic spray pyrolysis method shows improved activity which is higher than the samples prepared by hydrothermal process.

\section{Conclusion}

A facile and aerosol-assisted synthesis strategy was developed to prepare $\mathrm{Zn}_{x} \mathrm{Cd}_{1-x} \mathrm{~S}$ microspheres by using $\mathrm{Cd}\left(\mathrm{CH}_{3} \mathrm{COO}\right)_{2} \cdot 2 \mathrm{H}_{2} \mathrm{O}, \mathrm{ZnCl}_{2}$, and $\mathrm{CS}\left(\mathrm{NH}_{2}\right)_{2}$ as precursors. The composition dependence of the UV-vis spectra shows continuous red shift with increased $\mathrm{Cd}$ content. The photocatalytic activity tests show that samples prepared at the $\mathrm{Cd} / \mathrm{Zn}$ ratio of $1: 1$ possess the optimal activity for $\mathrm{MO}$ degradation under visible light. The conversion ratio of $\mathrm{MO}$ degradation is about $96 \%$. In this work, a new convenient route to synthesize ternary nonintegral stoichiometry compound $\mathrm{Zn}_{x} \mathrm{Cd}_{1-x} \mathrm{~S}$ microspheres is presented which exhibits potential for fabrication of other ternary semiconductors as photocatalysts and optoelectronic materials.

\section{Conflicts of Interest}

The authors declare that they have no conflicts of interest.

\section{Acknowledgments}

This work is supported by the Natural Science Foundation of Fujian Province (2015J01057, 2016J05042) and the Scientific
Project of Putian Science and Technology Bureau [2014S03, 2016S1001]. It was also supported by the research grant of Early Career Scheme (ECS 809813) from the Research Grant Council, Hong Kong Government.

\section{References}

[1] M. Li, J. Ouyang, C. I. Ratcliffe et al., "CdS magic-sized nanocrystals exhibiting bright band gap photoemission via thermodynamically driven formation," ACS Nano, vol. 3, no. 12, pp. 3832-3838, 2009.

[2] E. M. Chan, R. A. Mathies, and A. P. Alivisatos, "Size-controlled growth of CdSe nanocrystals in microfluidic reactors," Nano Letters, vol. 3, no. 2, pp. 199-201, 2003.

[3] I. Moreels, K. Lambert, D. Smeets et al., "Size-dependent optical properties of colloidal PbS quantum dots," ACS Nano, vol. 3, no. 10, pp. 3023-3030, 2009.

[4] J. Huang, W. Cheuk, Y. Wu, F. S. C. Lee, and W. Ho, "Efficient visible light photocatalytic oxidation of $\mathrm{NO}$ on $\mathrm{F}$ - and $\mathrm{N}$ codoped spherical $\mathrm{TiO}_{2}$ synthesized via ultrasonic spray pyrolysis," Journal of Nanomaterials, vol. 2012, Article ID 753429, 9 pages, 2012.

[5] Z. Xie, Y. Zhang, X. Liu et al., "Visible light photoelectrochemical properties of $\mathrm{N}$-doped $\mathrm{TiO}_{2}$-nanorod arrays from TiN," Journal of Nanomaterials, vol. 2013, Article ID 930950, 8 pages, 2013.

[6] M. Huang, J. Yu, C. Deng et al., "3D nanospherical $\mathrm{Cd}_{x} \mathrm{Zn}_{1-x} \mathrm{~S} /$ reduced graphene oxide composites with superior photocatalytic activity and photocorrosion resistance," Applied Surface Science, vol. 365, pp. 227-239, 2016.

[7] J. Li, L. Wu, L. Long, M. Xi, and X. Li, "Preparation of titania nanotube- $\mathrm{Cd}_{0.65} \mathrm{Zn}_{0.35} \mathrm{~S}$ nanocomposite by a hydrothermal sulfuration method for efficient visible-light-driven photocatalytic hydrogen production," Applied Surface Science, vol. 322, pp. 265-271, 2014.

[8] S. S. Srinivasan, J. Wade, and E. K. Stefanakos, "Visible light photocatalysis via $\mathrm{CdS} / \mathrm{TiO}_{2}$ nanocomposite materials," Journal of Nanomaterials, vol. 2006, Article ID 87326, 7 pages, 2006.

[9] A. Vázquez, D. B. Hernández-Uresti, and S. Obregón, "Electrophoretic deposition of CdS coatings and their photocatalytic activities in the degradation of tetracycline antibiotic," Applied Surface Science, vol. 386, pp. 412-417, 2016.

[10] W. Li, D. Li, Z. Chen et al., "High-efficient degradation of dyes by $\mathrm{Zn}_{x} \mathrm{Cd}_{1-x} \mathrm{~S}$ solid solutions under visible light irradiation," The Journal of Physical Chemistry C, vol. 112, no. 38, pp. 14943-14947, 2008.

[11] J. R. Ran, J. Zhang, J. G. Yu, and S. Z. Qiao, "Enhanced visiblelight photocatalytic $\mathrm{H}_{2}$ production by $\mathrm{Zn}_{x} \mathrm{Cd}_{1-x} \mathrm{~S}$ modified with earth-abundant nickel-based cocatalysts," Chemistry \& Sustainability, vol. 7, no. 12, pp. 3426-3434, 2014.

[12] J. Zhang, J. Yu, M. Jaroniec, and J. R. Gong, "Noble metalfree reduced graphene oxide- $\mathrm{Zn}_{x} \mathrm{Cd}_{1-x} \mathrm{~S}$ nanocomposite with enhanced solar photocatalytic $\mathrm{H}_{2}$-production performance," Nano Letters, vol. 12, no. 9, pp. 4584-4589, 2012.

[13] M. Antoniadou, V. M. Daskalaki, N. Balis, D. I. Kondarides, C. Kordulis, and P. Lianos, "Photocatalysis and photoelectrocatalysis using (CdS-ZnS)/TiO 2 combined photocatalysts," Applied Catalysis B: Environmental, vol. 107, pp. 188-196, 2011.

[14] K. Singh, S. Kumar, N. K. Verma, and H. S. Bhatti, "Photoluminescence characteristics of synthesized copper doped $\mathrm{Cd}_{1-x} \mathrm{Zn}_{x} \mathrm{~S}$ quantum dots," Journal of Materials Science: Materials in Electronics, vol. 20, no. 12, pp. 1178-1181, 2009. 
[15] Y.-F. Chai, G.-F. Huang, L.-L. Wang, W.-Q. Huang, and J. Zhou, "Enhanced photocatalytic activity and stability of $\mathrm{Zn}_{x} \mathrm{Cd}_{1-x} \mathrm{~S} /$ $\mathrm{TiO}_{2}$ nanocomposites synthesized by chemical bath deposition," Materials Letters, vol. 142, pp. 133-136, 2015.

[16] W. Li, D. Li, W. Zhang, Y. Hu, Y. He, and X. Fu, "Microwave synthesis of $\mathrm{Zn}_{x} \mathrm{Cd}_{1-x} \mathrm{~S}$ nanorods and their photocatalytic activity under visible light," Journal of Physical Chemistry $C$, vol. 114, no. 5, pp. 2154-2159, 2010.

[17] S. Zu, Z. Wang, B. Liu, X. Fan, and G. Qian, "Synthesis of nano- $\mathrm{Cd}_{x} \mathrm{Zn}_{1-x} \mathrm{~S}$ by precipitate-hydrothermal method and its photocatalytic activities," Journal of Alloys and Compounds, vol. 476, no. 1-2, pp. 689-692, 2009.

[18] Y. Wang, J. C. Wu, J. W. Zheng, R. R. Jiang, and R. Xu, "Ni ${ }^{2+}$ doped $\mathrm{Zn}_{x} \mathrm{Cd}_{1-x} \mathrm{~S}$ photocatalysts from single-source precursors for efficient solar hydrogen production under visible light irradiation," Catalysis Science \& Technology, vol. 2, no. 3, pp. 581588, 2011.

[19] J. H. Zhong, Y. Zhang, C. Q. Hu et al., "Supercritical solvothermal preparation of $\mathrm{Zn}_{x} \mathrm{Cd}_{1-x} \mathrm{~S}$ visible photocatalyst with enhanced activity," Journal of Materials Chemistry A, vol. 2, no. 1, pp. 19641-19647, 2014.

[20] W. Z. Wang, I. Germanenko, and M. S. El-Shall, "Room-temperature synthesis and characterization of nanocrystalline CdS, $\mathrm{ZnS}$, and $\mathrm{Cd}_{x} \mathrm{Zn}_{1-x} \mathrm{~S}$," Chemistry of Materials, vol. 14, no. 7, pp. 3028-3033, 2002.

[21] K.-T. Chung and S. E. Stevens Jr., "Degradation of azo dyes by environmental microorganisms and helminths," Environmental Toxicology and Chemistry, vol. 12, no. 11, pp. 2121-2132, 1993.

[22] A. Gottlieb, C. Shaw, A. Smith, A. Wheatley, and S. Forsythe, "The toxicity of textile reactive azo dyes after hydrolysis and decolourisation," Journal of Biotechnology, vol. 101, no. 1, pp. 4956, 2003.

[23] Y. Li, M. Ye, C. Yang, X. Li, and Y. Li, "Composition- and shape-controlled synthesis and optical properties of $\mathrm{Zn}_{x} \mathrm{Cd}_{1-x} \mathrm{~S}$ alloyed nanocrystals," Advanced Functional Materials, vol. 15, no. 3, pp. 433-441, 2005.

[24] L. V. Azaroff, Elements of X-Ray Crystallography, McGraw-Hill Company, Japan, 1968.

[25] Y. Liu, J. A. Zapien, Y. Y. Shan, C.-Y. Geng, C. S. Lee, and S.-T. Lee, "Wavelength-controlled lasing in $\mathrm{Zn}_{x} \mathrm{Cd}_{1-x} \mathrm{~S}$ single-crystal nanoribbons," Advanced Materials, vol. 17, no. 11, pp. 1372-1377, 2005.

[26] L. Wang, Y. Jiang, C. Wang et al., "Composition-controllable synthesis and optical properties of non-integral stoichiometry compound $\mathrm{Zn}_{x} \mathrm{Cd}_{1-x} \mathrm{~S}$ nanorods," Journal of Alloys and Compounds, vol. 454, no. 1-2, pp. 255-260, 2008.

[27] J. Shi, H. Yan, X. Wang, Z. Feng, Z. Lei, and C. Li, “Compositiondependent optical properties of $\mathrm{Zn}_{x} \mathrm{Cd}_{1-x} \mathrm{~S}$ synthesized by precipitable-hydrothermal process," Solid State Communications, vol. 146, no. 5-6, pp. 249-252, 2008.

[28] J. A. Villoria, R. M. N. Yerga, S. M. Alzahrani, and J. L. G. Fierro, "Photocatalytic hydrogen production on $\mathrm{Cd}_{1-x} \mathrm{Zn}_{x} \mathrm{~S}$ solid solutions under visible light: influence of thermal treatment," Industrial \& Engineering Chemistry Research, vol. 49, no. 15, pp. 6854-6861, 2010.

[29] D. V. Petrov, B. S. Santos, G. A. L. Pereira, and C. De Mello Donegá, "Size and band-gap dependences of the first hyperpolarizability of $\mathrm{Cd}_{x} \mathrm{Zn}_{1-x} \mathrm{~S}$ nanocrystals," Journal of Physical Chemistry B, vol. 106, no. 21, pp. 5325-5334, 2002.

[30] Y. Zhou, Y. Wang, T. Wen et al., "Mesoporous $\mathrm{Cd}_{1-x} \mathrm{Zn}_{x} \mathrm{~S}$ microspheres with tunable bandgap and high specific surface areas for enhanced visible-light-driven hydrogen generation," Journal of Colloid and Interface Science, vol. 467, pp. 97-104, 2016.

[31] J. Xu, C. Pan, and K. Domen, "Photocatalytic overall water splitting on the perovskite-type transition metal oxynitride $\mathrm{CaTaO}_{2} \mathrm{~N}$ under visible light irradiation," Chemical Communications, vol. 51, no. 33, pp. 7191-7194, 2015. 

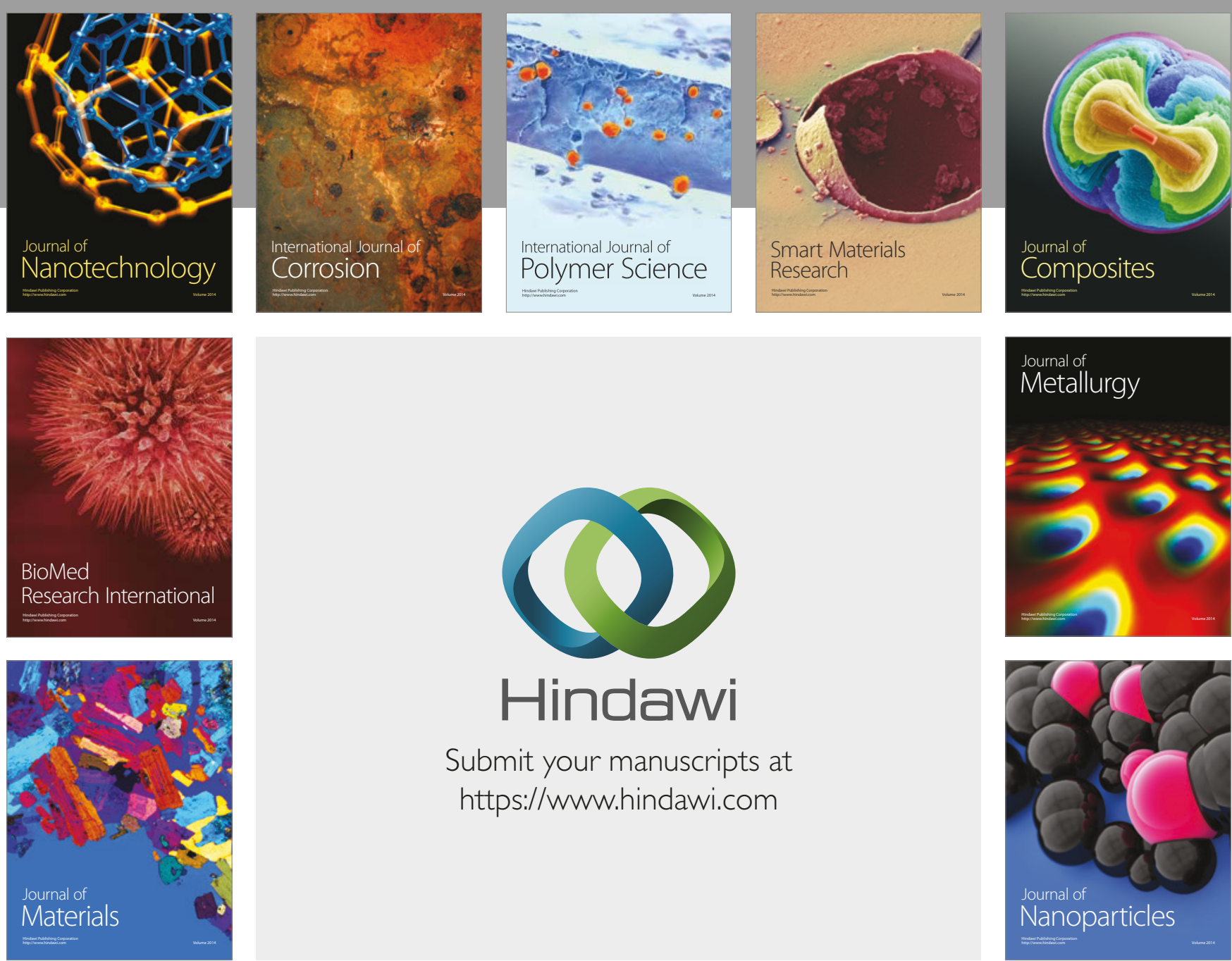

\section{Hindawi}

Submit your manuscripts at

https://www.hindawi.com
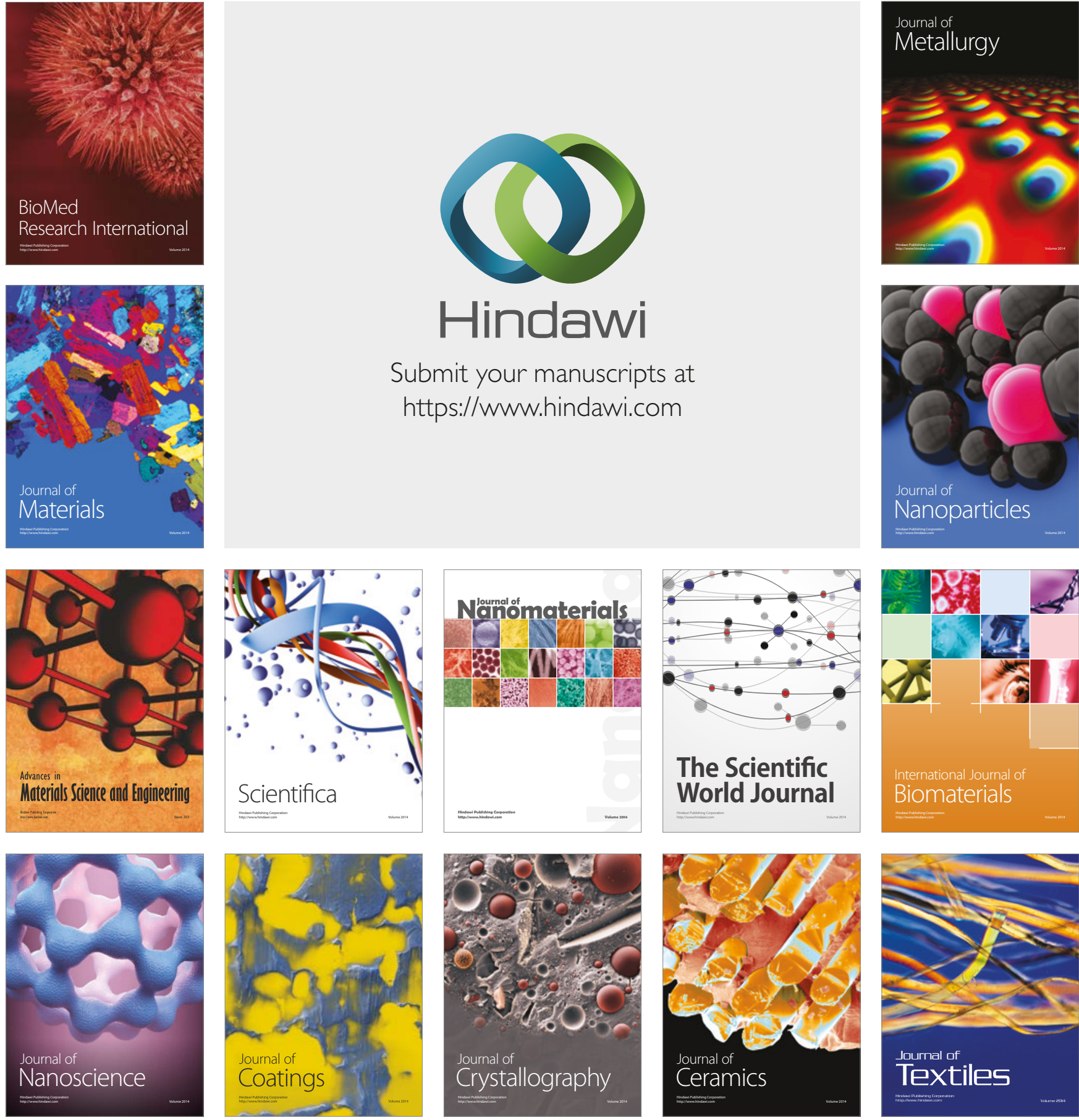

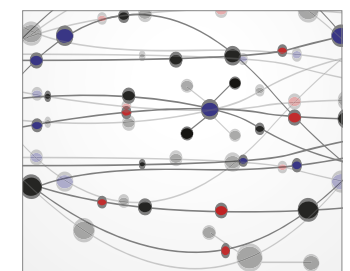

The Scientific World Journal
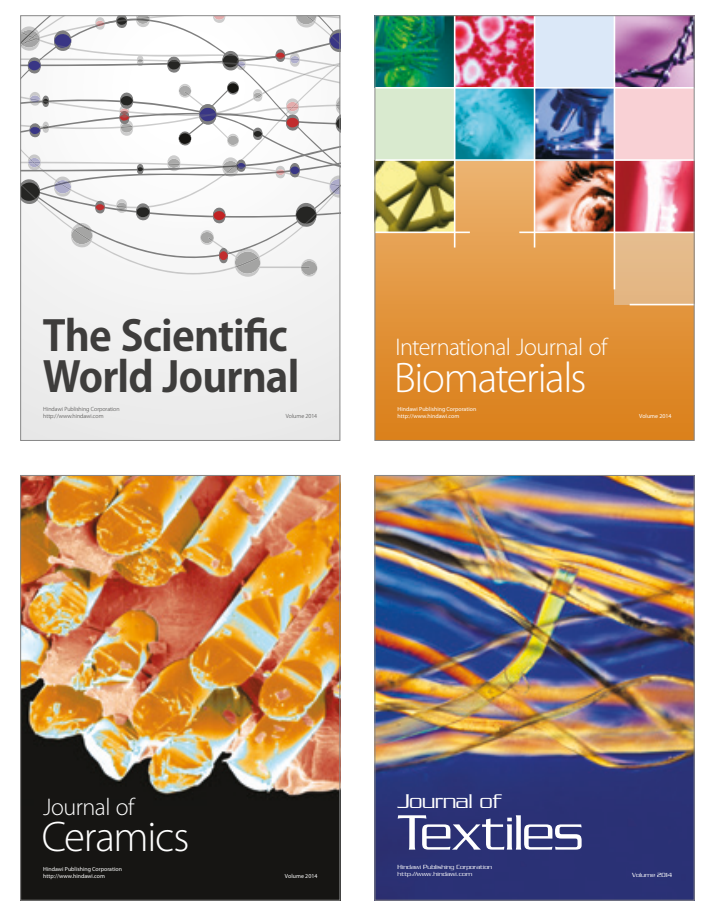